\title{
Article \\ Considering Human Variability in the Design of Safe Interaction with Agricultural Machinery: The Case of Foldable Roll-Over Protective Structure (FROPS) Manual Handling
}

\author{
Margherita Micheletti Cremasco ${ }^{1,+}+\mathbb{D}$, Lucia Vigoroso ${ }^{2,+}$, Federica Caffaro ${ }^{3, *(\mathbb{D}}$, Giuseppe Paletto ${ }^{2}$ \\ and Eugenio Cavallo ${ }^{2}$ D \\ 1 Department of Life Sciences and Systems Biology, University of Turin, Via Accademia Albertina, 13, \\ 10123 Torino, Italy; margherita.micheletti@unito.it \\ 2 Institute of Sciences and Technologies for Sustainable Energy and Mobility (STEMS), National Research \\ Council of Italy (CNR), Strada delle Cacce, 73, 10135 Torino, Italy; lucia.vigoroso@stems.cnr.it (L.V.); \\ giuseppe.paletto@stems.cnr.it (G.P.); eugenio.cavallo@stems.cnr.it (E.C.) \\ 3 Department of Education, University of Roma Tre, Via del Castro Pretorio 20, 00185 Rome, Italy \\ * Correspondence: federica.caffaro@uniroma3.it \\ + These authors contributed equally to this work.
}

\section{check for} updates

Citation: Micheletti Cremasco, M. Vigoroso, L.; Caffaro, F.; Paletto, G.; Cavallo, E. Considering Human Variability in the Design of Safe Interaction with Agricultural Machinery: The Case of Foldable Roll-Over Protective Structure (FROPS) Manual Handling. Agronomy 2021, 11, 1303. https://doi.org/ 10.3390/agronomy11071303

Academic Editor: Daniela Lovarelli

Received: 10 May 2021

Accepted: 11 June 2021

Published: 27 June 2021

Publisher's Note: MDPI stays neutral with regard to jurisdictional claims in published maps and institutional affiliations.

Copyright: (c) 2021 by the authors. Licensee MDPI, Basel, Switzerland. This article is an open access article distributed under the terms and conditions of the Creative Commons Attribution (CC BY) license (https:/ / creativecommons.org/licenses/by/ $4.0 /)$.

\begin{abstract}
The foldable roll-over protective structure (FROPS) protects the operators against fatal injuries in tractor roll-over accidents. However, a rear-mounted FROPS is often folded down or removed. In the present study, the accessible zones and grasping areas in a rear-mounted FROPS were redesigned and adapted to the 5th, 50th, and 95th European human anthropometric percentiles to enhance its correct and comfortable use. Then, a rod was proposed as a design solution to make the roll-bar grasping areas fall within the new accessible zones. The rod prototype increased roll-bar reachability and facilitated the raising handling, especially for shorter users. The present study results and the accessible zones redesigned, taking into account the human percentiles, will be helpful in rethinking reachability issues in manual handling of machinery components, to support the correct behaviours, and make human-machine interaction more comfortable and safer for all.
\end{abstract}

Keywords: ergonomics; FROPS; human variability; tractor safety; reach

\section{Introduction}

Tractor roll-over is the most frequent type of accident in the agricultural sector [1,2]. The roll-over protective structures (ROPS), i.e., safety cab, frame, or roll-bar, are mechanical structures fitted on agricultural and forestry tractors. Together with a driver's retention system, the seatbelt, they avoid or limit the risks to the driver resulting from roll-over of the vehicle during normal use [3,4]. ROPSs have been adopted on tractors since the 1980s, when significant safety and health, and ergonomics progress had been introduced [5]. Proving to be effective measures to prevent injuries during tractor roll-over, they are mandatorily fitted on tractors in many countries [6] because of requirements from public road circulation and occupational safety and health regulations [7]. Foldable two-post ROPS (FROPS) have been designed to facilitate tractor operation in low overhead clearance zones: orchards and vineyards and confined spaces, such as greenhouses and animal husbandry buildings [8]. FROPS are often fitted on narrow tractors (i.e., having at least one axle with a track width not larger than $1150 \mathrm{~mm},[9,10])$. Two different categories of narrow tractors are internationally recognised under ROPS safety and health regulation requirements [11,12]: tractors with ROPS mounted on the front of the driving station, with a maximum permitted unladen mass of $3500 \mathrm{~kg}$ [13], and ROPS fitted on the back of the driver's seat, without any unladen mass upper limit, unless they have a reversible driver's position or reversible seat and steering wheel (in this case the maximum permitted unladen mass is limited to $3500 \mathrm{~kg}$ ) [14]. 
FROPS also find application on bigger and higher power standard tractors (without any track width and mass limitation regarding safety and health ROPS requirements [3]) when manufacturers need to curb the cost, and the purchase price, in markets with limited economic possibilities, or on entry-level models; frequently, in these cases, the foldable roll-bars are adopted to reduce space during transport and storage at the dealers' and farmers' facilities. According to the European Agricultural Machinery Association [15], approximately 43,000 and 38,000 out of 191,000 and 177,000 tractors registered in 2019 and 2018, respectively, in European Union (EU) countries, are equal to or under $37 \mathrm{~kW}$ (50 hp), and most likely belong to the narrow tractor category and are potentially equipped with a FROPS. Hence, standard tractors are the most represented category where, even though less common, the rear-FROPS are marketed.

Generally, the FROPS comprises two lower steel components, one for each side of the tractor, mounted in front of or on the back of the driving seat, and an upper inverted U-shaped folding steel tube. The lower and upper parts are joined at a pivot point by a couple of pins on each side of the protective structure, making it possible to fold the upper part frontward or rearward, based on the FROPS type (Figure 1). The folding operation is generally manual, even though some dimensions and mass of the components may overcome the human handling capacity, as observed in previous works $[16,17]$ on standard tractors.
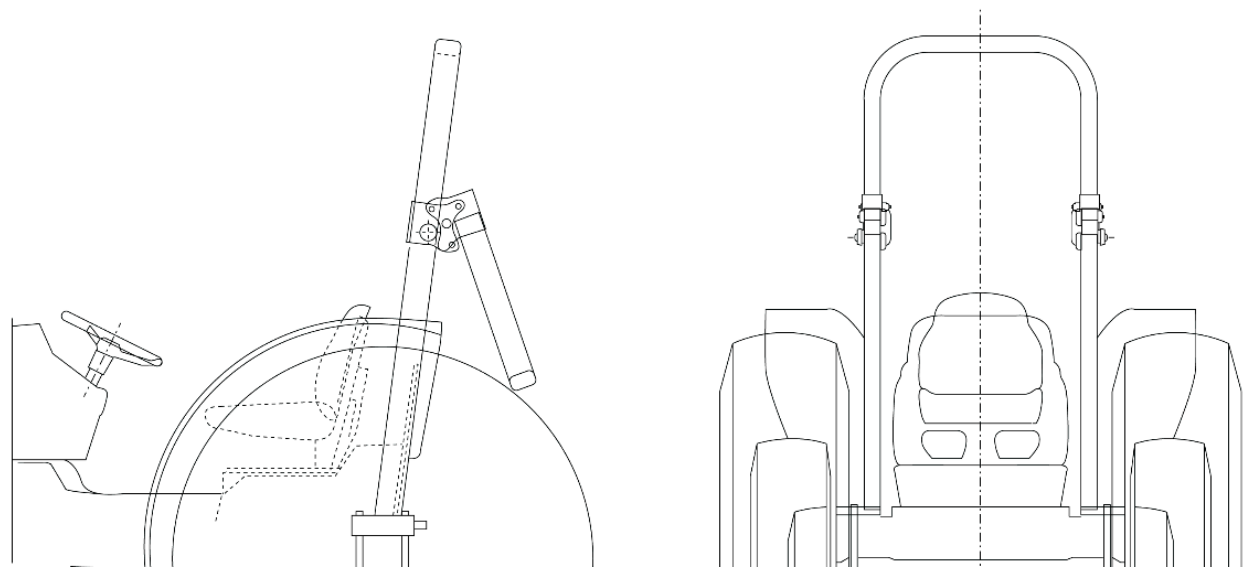

Figure 1. Side (with upper folding component in upright and folded position) and front views of a rear-FROPS.

FROPS, as all ROPS, are designed to absorb the energy developed by the impact with the ground in case of overturn, but with a limited deflection to avoid the infringement of the "clearance zone", a standardised volume representing the space occupied by the driver "when seated either inside the envelope of the structure or within a space bounded by a series of straight lines from the outer edges of the structure to any part of the tractor that might come into contact with flat ground and that is capable of supporting the tractor in that position if the tractor overturns" [3] (p. 3). Recent surveys have revealed a new issue about FROPS-equipped tractors and the fatality rate in agriculture in many developed countries: the number of fatal accidents and severe injuries in tractor roll-over accidents with folded down or removed FROPS has increased in the last years [18-21]. The manual handling, considered a strenuous operation, and the poor reachability of the rear-mounted FROPS have been recognised as the leading causes for removing or leaving the FROPS in a folded down position $[22,23]$. Reachability issues especially affect shorter operators, who reported the need to redesign the foldable roll-bar able to respect users' anthropometric variability $[16,17]$.

According to the ergonomics literature [24-28], the anthropometric and functional variability in the interaction with sizes, volumes, and movements of the machines should be considered to ensure that the machines address, as much as possible, the needs of 
the broadest audience. Indeed, taking into account reachability, quality of the grip, and postures required to operate machinery parts increases the overall system safety and comfort in use [29,30]. In addition, the European Machinery Directive [31] indicates that the anthropometric variability and ergonomic principles must be taken into account to improve the human-machinery interaction and minimise operators' discomfort and fatigue.

\section{State of the Art Regarding FROPS Manual Handling Requirements and Aim of the Present Study}

Previous studies aiming to promote the comfortable and safe handling of rear-mounted FROPS resorted mainly to technical engineering approaches to develop mechanical solutions $[32,33]$ to ensure the clearance zone is not infringed during strength tests and protect the operator in case of roll-over $[12,34,35]$. Although the ergonomic issues during FROPS operations have increasingly received attention [8,34], few previous studies stressed the role of anthropometric variability in determining the quality of the human-FROPS interaction; these studies highlighted the need for some redesign to enhance comfort and safe use, especially for shorter operators who are adopting awkward postures and unsafe climbing behaviours when handling the roll-bar [16,17]. The difficulties and the improper behaviours that emerged from these previous field observations represented the rationale of the present study and the resulting proposal of FROPS improvement.

The Organization for Economic Co-operation and Development (OECD) Standard Code 6 for the Official Testing of Agricultural and Forestry Tractors [13] has introduced, since 2016, optional minimum ergonomic requirements to improve the manoeuvrability of front-FROPS fitted on narrow tractors. In 2017, the same requirements were also extended to narrow tractors with rear-FROPS [14]. Such requirements were incorporated, becoming mandatory, in the EU technical requirements for the type-approval of narrow new agricultural and forestry tractors [10]. The OECD Code 7 [14] also acknowledges that tractors with one of the axles less than $1150 \mathrm{~mm}$ where a rear-FROPS is fitted do not have any mass limit unless they have a reversible driver's position or reversible seat and steering wheel; in this relatively uncommon case, the maximum permitted unladen mass is limited to $3500 \mathrm{~kg}$. Therefore, despite their reduced track, the narrow tractors can take a considerable vertical shape, similar to those of standard tractors, making it practically impossible to raise/lower the protective structure standing on the ground.

The OECD Codes $[13,14]$ define the grasping area as "the portion of the ROPS and/or additional handle fitted to the ROPS where the operator is allowed to carry out the raising/lowering operations" (Figure 2a) and the accessible zones in the human-FROPS interaction as "the volume where an operator standing on the ground can apply a force to raise/lower the ROPS" [14] (p. 22). The three accessible zones are defined as Zone I-comfort zone, Zone II-accessible zone without forward-leaning of the body, and Zone III-accessible zone with forward-leaning of the body. The two areas above Zone II and Zone III, indicated as Extension of Zone II and Extension of Zone III, are the acceptable extensions of the two respective accessible zones (Figure $2 b$ ).

In the accessible zones depicted in the OECD Code 7 [14], the only measurement provided is the operator's eye height, referable to an approximately $1.60 \mathrm{~m}$ tall person (Figure 2b), without any specification regarding either the reason for choosing the manikin characteristics or the anthropometric reference dataset. In the human-machine interaction, beyond the human anthropometric variability, it is relevant to also consider tractor dimensions which are not taken into account in the drawings of OECD Code 7. Indeed, observing these drawings, we can infer that the machine represented is a "small tractor" (fully raised FROPS is as tall as the human figure depicted) and it is not representative of the actual measurements range of tractors with rear-mounted FROPS [3].

Therefore, starting from all the previous considerations, the present study has a threefold purpose: (a) to resize the accessible zones provided by the OECD Codes (using the same 2D graphical style), adjusting them to users' anthropometric and functional variability, (b) to develop a prototype design solution to increase FROPS reachability based on the redesigned accessible zones, and (c) to test the suggested solution with real users 
characterised by different anthropometric measurements, to investigate benefits in terms of safety and comfort in roll-bar handling.

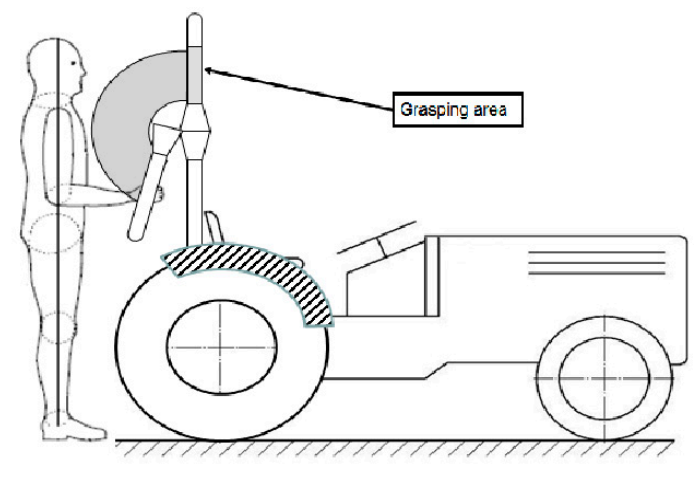

(a)

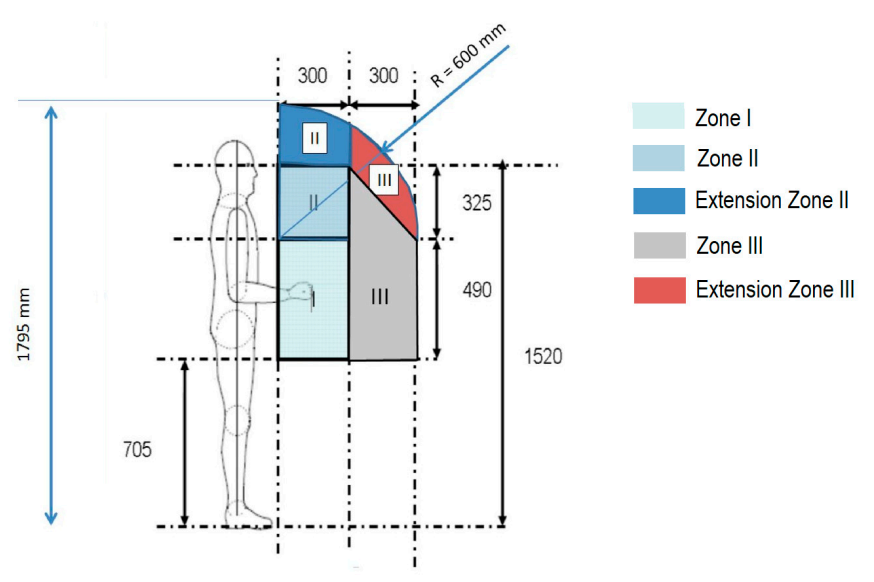

(b)

Figure 2. OECD requirements to guarantee a safe and comfortable FROPS operation: (a) accessible zones to handle the roll-bar in front of its trajectory (OECD Standard Code 7), and (b) grasping areas (OECD Standard Code 7). Reprinted with permission from [14].

In the following sections, we will describe the different phases which led to the redesign of the accessible zones and the development of the prototyped solution. In particular: (a) the redesign of both the human figure and the tractor starting from a set of anthropometric dimensions and previous on-field observations to account for human variability and tractor dimensions; (b) the integration of the analysis of the dimensional characteristics of the human figure and the tractor with functional aspects regarding upper limbs reachability and movements; and (c) the evaluation of a possible design solution, i.e., a rod, to increase FROPS reachability and validate graphical representation with a group of users.

\section{Materials and Methods}

\subsection{Development of the Human Manikin}

According to the ergonomic requirements, the adoption of percentiles of anthropometric variables is the most recommended approach in design. Often, the 5th and 95th percentiles are used to define the minimum and maximum values that are considered [36,37]. As reported in Pheasant and Haslegrave [28], many sources of anthropometric data for different populations can be found in the extant literature and international standards [37-41], but "few of the surveys for either national or special populations provide a comprehensive set of anthropometric dimensions (if such a set were possible)" [28] (p. 53). Based on this, "designers are often faced with the need to estimate dimensions for some design parameters even when using the most comprehensive data set" [28] (p. 53).

For the aims of the present study, three percentiles, respectively the 5th, the 50th, and the 95th percentiles, were considered, and some specific measures of the body segments were adopted considering the relation between the human reachability and the elements of interaction with the tractor. Thus, 10 anthropometric variables, as defined in International Organization for Standartization (ISO) 7250-1 [42], were considered: two variables (the eye height and the crotch height) corresponded to those considered in the OECD Codes, whereas the other eight variables were stature, forward reach, hand length and foot length, shoulder height, elbow height, tibiale height, and elbow-wrist length (Figure 3). Among the available anthropometric databases, the dataset reported in Jurgens et. al. [37] was considered as the most comprehensive for the 10 variables of interest and all the three percentiles considered (5th, 50th, and 95th). In addition, this dataset has been largely 
adopted in the European and international standards for anthropometry and humanmachine interaction [43,44]. The measurements provided by Jurgens et al. [37] represent the average values for both sexes in a sample of 3 million Europeans with age ranging between 18 and 60 years. Moreover, "a compromise concerning a differentiated solution was found in defining the median (50th percentile) of all measure of the European population by way of the all European calculation, while the limiting percentile 5th and 95th were to be set according to the countries hosting the highest and the lowest body measures in their population respectively" [37] (p. 4) (Figure 4).

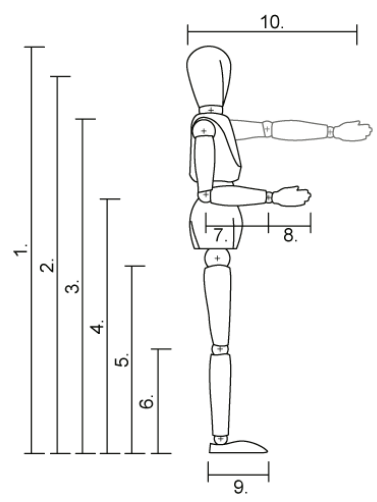
1. Stature (body height)
6. Tibiale height
2. Eye height
7. Elbow-wrist length
3. Shoulder height
8. Hand length
4. Elbow height
9. Foot length
5. Crotch height
10. Forward reach (grip axis)

Figure 3. The ten measurements considered to represent the human figure in the present study. Based on Jurgens et al. [37] dataset (in which the anthropometric measurements of male and female individuals were considered together), the human figure is represented through a sexless manikin.

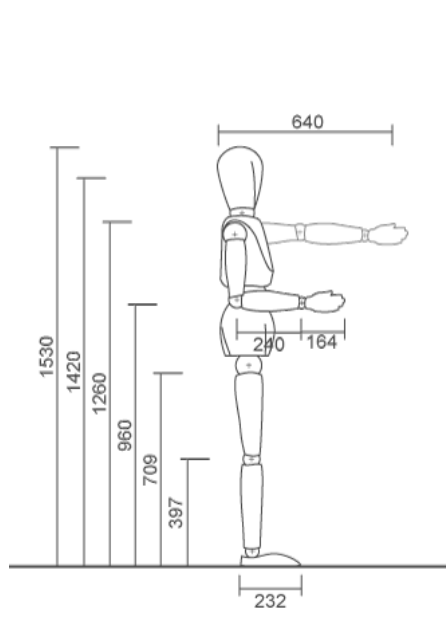

(a)

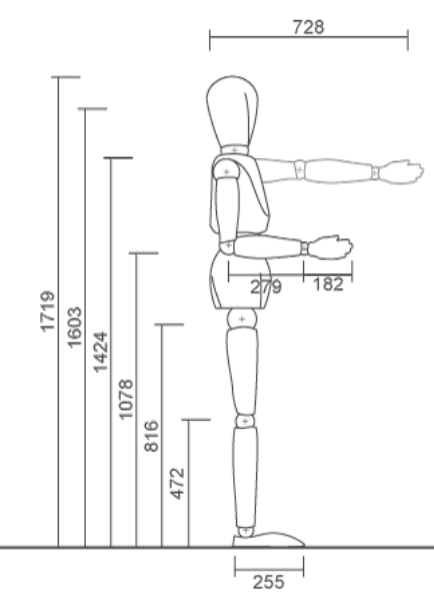

(b)

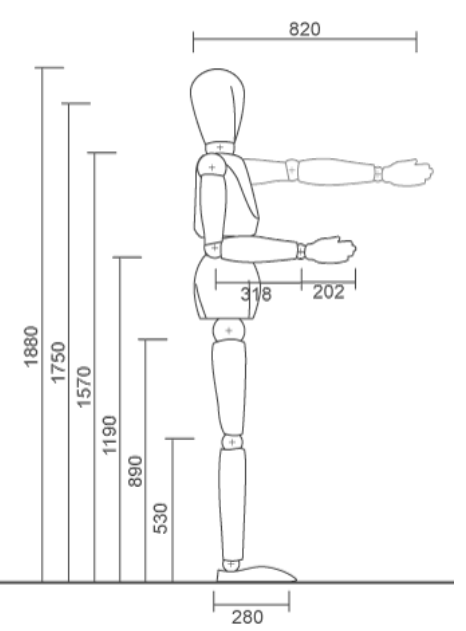

(c)

Figure 4. Human figure representations based on European anthropometric data [37] considering the ten variables of interest: (a) 5th percentile, (b) 50th percentile, and (c) 95th percentile.

In conclusion, based on the only operators' measurement provided in OECD Code 7 (i.e., the eye height that corresponds to $1.52 \mathrm{~m}$ ), the stature of the human figure reported on the OECD Codes is estimated to be just over the 5th percentile of an average European subject, and limbs length is between the 5th and the 50th percentile [37].

\subsection{Development of the Tractor Model}

The enhanced image of the tractor has been defined based on the three most important measurements related to the points of interaction with FROPS as observed in previous studies on standard tractors [16,17]: (1) distance from ground to FROPS in the folded-down position ( $45^{\circ}$ angle between the upper folding part and the lower component of FROPS); 
(2) distance from ground to FROPS pivot pin, which corresponds to the height of FROPS raised forming a $90^{\circ}$ angle; (3) distance from FROPS pivot pin to the top of the fully raised roll-bar (Figure 5).

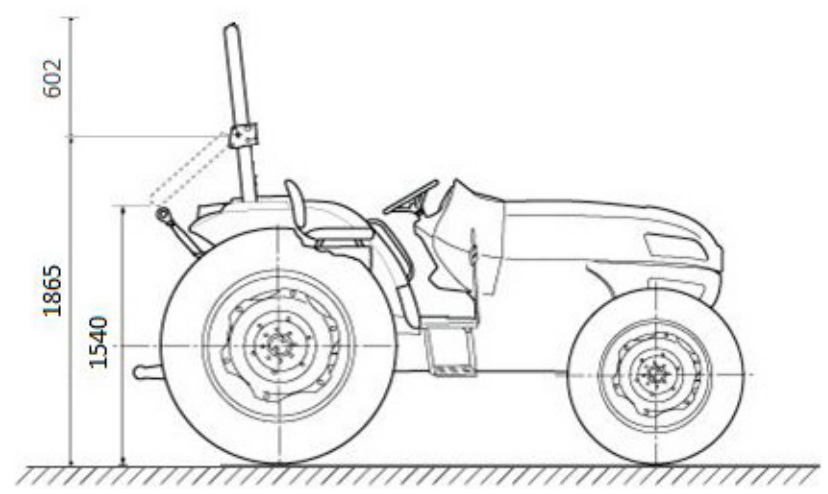

Figure 5. Representation of the tractor, based on the average measurements collected on field.

\subsection{Development of the Accessible Zones through the Merge of the Human and Tractor Representations}

After having graphically and metrically defined both the human figure and the tractor features, the manikins of the 5th, 50th, and 95th percentiles were overlapped to the tractor representation to easily identify the interaction points between the human figure and the machine. The postures of the manikins and their distances from the tractor were designed based on those detected in previous field observations $[16,17]$. Only as a graphical reference, the manikins reported in the results section have been depicted with the right arm raised, simulating the grasp of the roll-bar when it was at $45^{\circ}$, and the left arm extended, simulating the grasp of the roll-bar when it was at $90^{\circ}$.

To develop the accessible zones adapted to the three percentiles considered, the existing accessible zones used in the OECD Codes were scaled by adopting specific anatomical landmarks and body measurements as a reference. In particular, body measurements as the crotch height and the eye height, which correspond to the lower limit of the accessible Zone I and to the upper limit of the accessible Zone II, respectively, were used as referring points.

Furthermore, with the aim to redesign the accessible zones respecting the ergonomic principles, besides the human dimensional characteristics, the functional ones have also been considered. Thus, the present study also took into account the results summarized in KAN Study 50 [45] (Table 1); in particular it reports the relationship between the height of the gripping point from the ground and the maximum forces applicable to operate a swinging component of the machine, to determine the optimal height from the ground to exert as little effort as possible. Considering the position of the roll-bar to be moved when it is grasped by the operators the maximum forcesvalues at $45^{\circ}$ and $90^{\circ}$ for the lowering and lifting task for male operators from the KAN Study 50 were considered. Such forces area summarized in Table 1.

Table 1. Maximum applicable forces and height from the ground of the gripping point for lifting and lowering swivelling manually operated parts according to the KAN study 50 (2013) when they are at $90^{\circ}$ and $45^{\circ}$.

\begin{tabular}{|c|c|c|c|c|}
\hline \multirow[b]{2}{*}{ Height from the Ground } & \multicolumn{2}{|c|}{ Swivelling Manually Operated Parts at $45^{\circ}$} & \multicolumn{2}{|c|}{ Swivelling Manually Operated Parts at $90^{\circ}$} \\
\hline & Lowering & Lifting & Lowering & Lifting \\
\hline 1920 & - & - & $500 \mathrm{~N}$ & $500 \mathrm{~N}$ \\
\hline 1610 & $300 \mathrm{~N}$ & $500 \mathrm{~N}$ & - & - \\
\hline 1380 & $300 \mathrm{~N}$ & $400 \mathrm{~N}$ & - & - \\
\hline 1220 & - & - & $500 \mathrm{~N}$ & $300 \mathrm{~N}$ \\
\hline 790 & $500 \mathrm{~N}$ & $500 \mathrm{~N}$ & - & - \\
\hline
\end{tabular}




\subsection{Test with Real Users to Validate the Graphical Representation}

At the end of the whole redesign process of the accessible zones, a prototype solution to increase the FROPS reachability was developed, fixed on a sample of FROPS and tested with three real users representative of the three percentiles considered (5th, 50th, and 95th) to evaluate benefits in terms of safety and comfort in roll-bar handling. Participants were three young novice farmers. For safety reasons, the prototype of the handle was fixed on an ad hoc structure which simulated the actual dimensions of a real tractor, whereas some specific obstacles, such as those related to the rear wheels, were marked on the floor using a white adhesive tape, asking participants not to cross that limit during the FROPS handling tasks.

\section{Results}

\subsection{Graphical Representation of the Accessible Zones Based on Human Manikins}

The size of the newly developed accessible zones increases as the measurements of the three human figures grow, as reported in Figure 6 (with the three percentiles depicted separately) and Figure 7 (with the three percentiles overlapped). The figures highlighted the variation of the accessible zones based on the percentile figure considered, extended from $1660 \mathrm{~mm}$ to $2070 \mathrm{~mm}$ in height and from $556 \mathrm{~mm}$ to $700 \mathrm{~mm}$ in width, with all its distinct areas depicted proportionally.

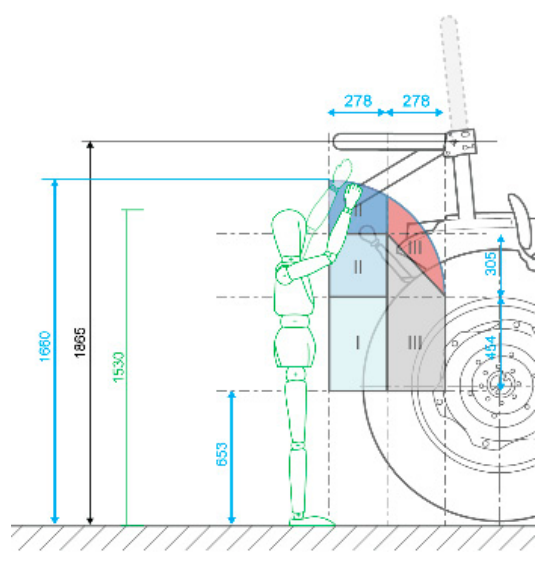

(a)

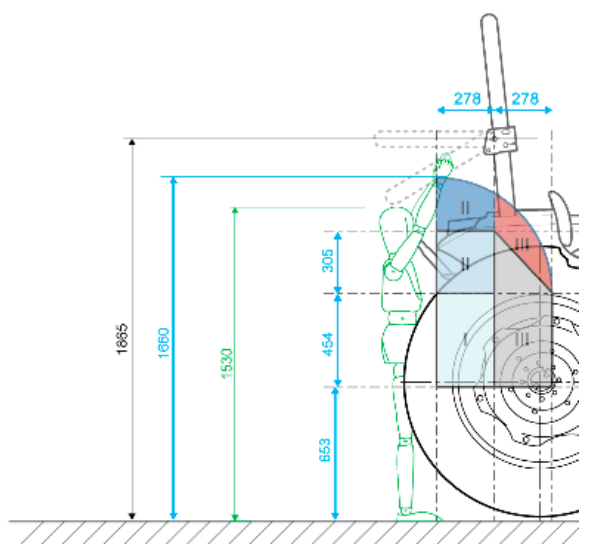

(d)

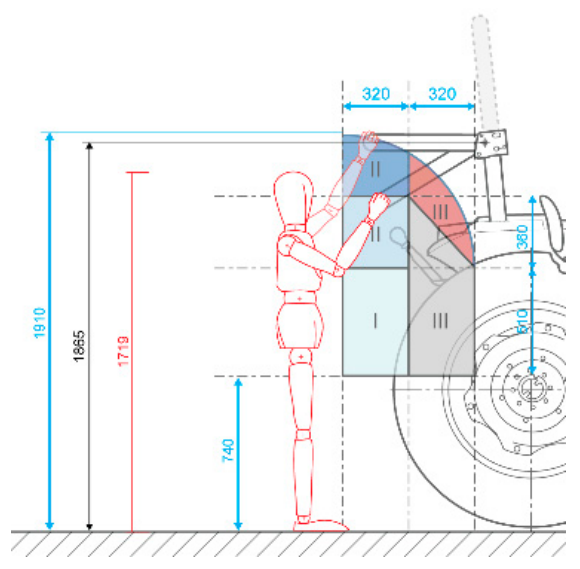

(b)

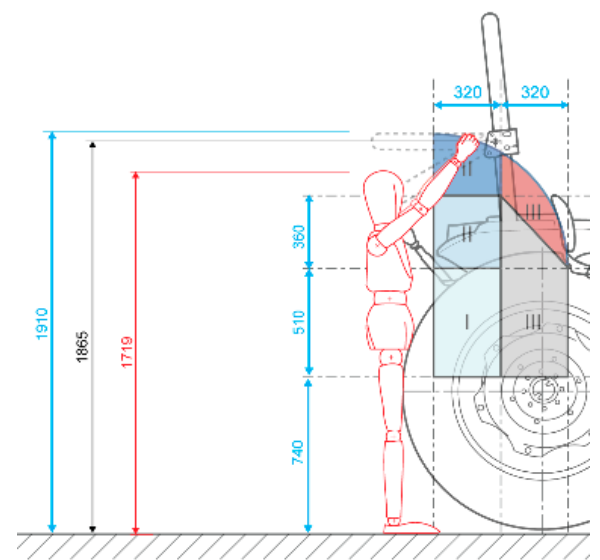

(e)

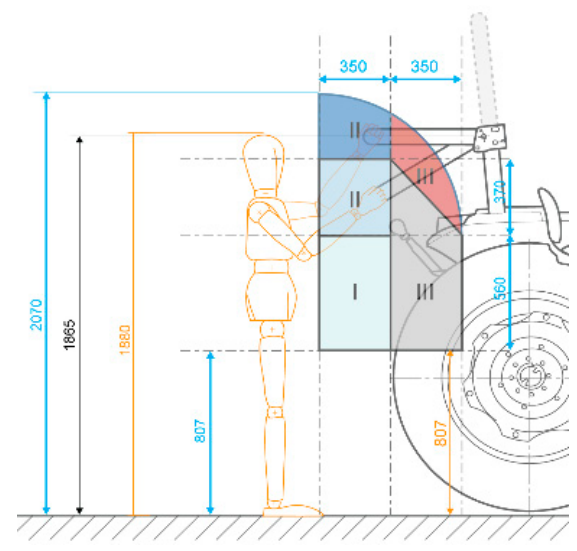

(c)

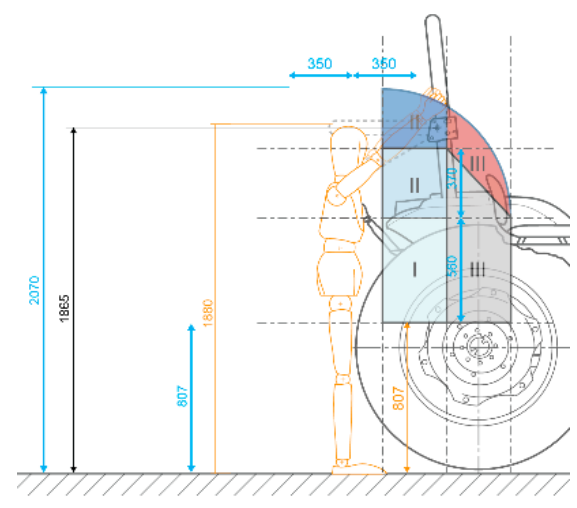

(f)

Figure 6. Measurements of the accessible zone redesigned based on the three percentiles figures: (a) 5 th percentile, (b) 50th percentile, (c) 95 th percentile when the FROPS is at $45^{\circ}$ and $90^{\circ}$, and (d) 5 th percentile, (e) 50th percentile, (f) 95 th percentile when the FROPS is in the upright position. 


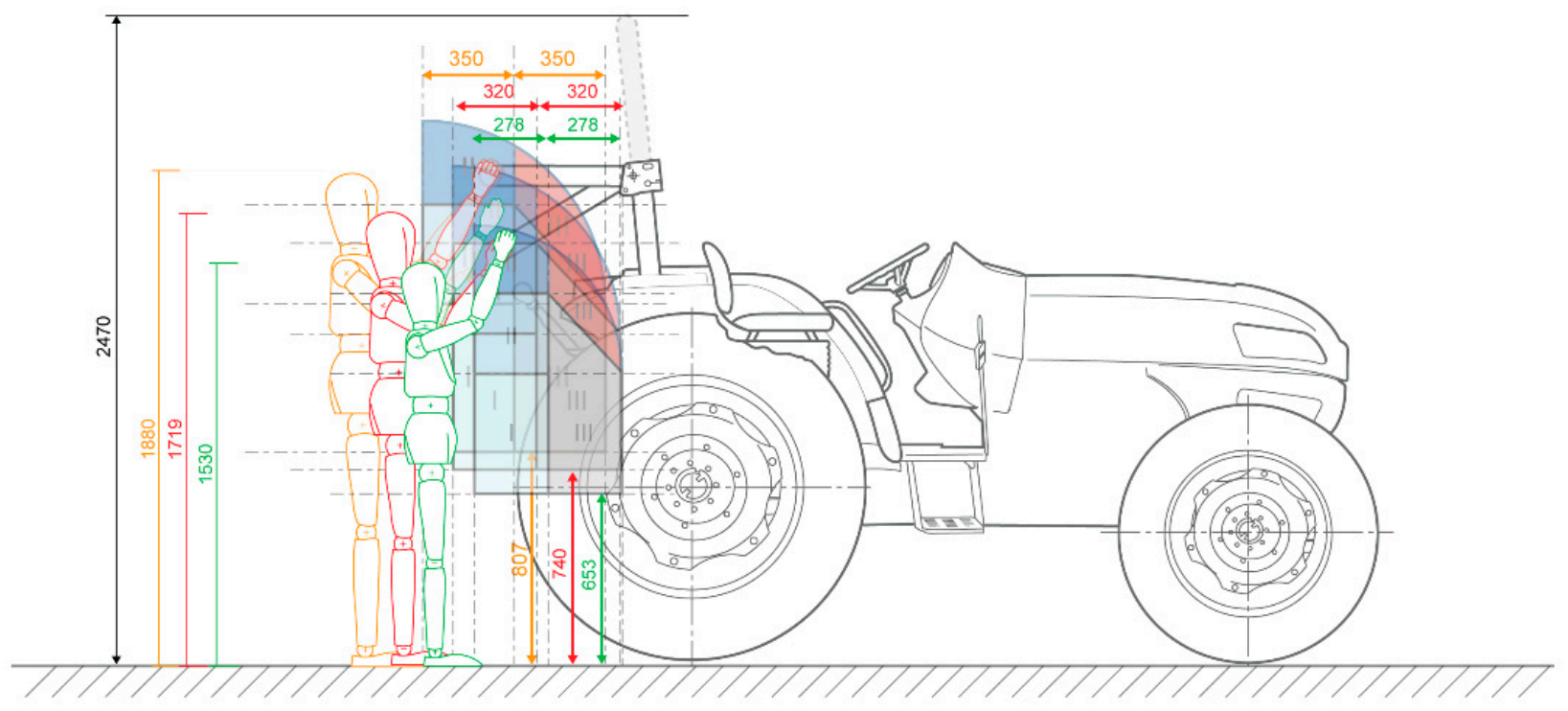

Figure 7. The three percentiles figures and their respective accessible zones, overlapped.

When the FROPS is in the folded-down position the manikins can reach the roll-bar by handling it in Zone II and extension of Zone II. In particular, the gripping point is on the upper limit of the Extension of Zone II in the case of the 5th percentile figure, near the lower limit of the same zone for the 50th percentile figure, and within Zone II for the 95th percentile figure. On the other hand, when the roll bar is at $90^{\circ}$, the 5 th percentile figure cannot reach the roll-bar since it is above the extension of Zone II, the 50th percentile figure's gripping point corresponds exactly with the limit of the same area, whereas the 95th percentile figure can reach the FROPS, handling it within the extension of Zone II. Furthermore, from the representations, it is possible to assume that, when the FROPS is fully lowered (i.e., at $0^{\circ}$ ), the gripping point of the roll-bar is on the edge between Zone II and the extension of Zone II for the 5th percentile figure, within Zone II for the 50th percentile, and on the border between Zone I and Zone II for the 95th percentile figure. However, it is useful to remember that this latter condition did not occur in the actual contexts observed in previous on-field studies, since the roll-bar was not completely folded down, but it maintained an angle of about $45^{\circ}[16,17]$.

In addition, in Figures 6 and 7, the manikins were not represented with hands and arms raised when the FROPS has angle over $90^{\circ}$ and in the upright position, since it was previously noted that most operators were not always able to reach and grip FROPS in that specific condition [16,17]. Indeed, this condition would be representable only for for users belonging to the 95th percentile, who have to get closer to the tractor machinery and need to change their hand position on the FROPS from the horizontal crossbar to the vertical bars. This means that users placed their hands closer to the pivot pin. However, all the three percentiles considered have their hands outside the accessibility zone.

\subsection{The Developed Accessible Zones Supported by the Maximum Applicable Forces}

Starting from elements depicted in Figure 6, the grasping area was considered and the real distances from the ground to the manually operated part (i.e., the gripping point of the roll-bar) were compared with those reported in the KAN Study 50 (2013) for swivelling agricultural machines manually operated parts in lifting and lowering movements (Figure 8). The comparison was useful to verify the reliability of the proposed accessible zones with respect to the required posture. 


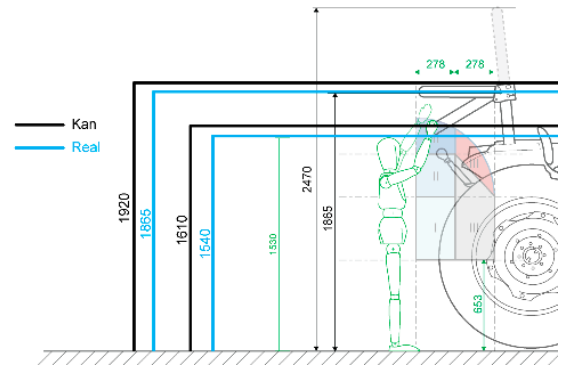

(a)

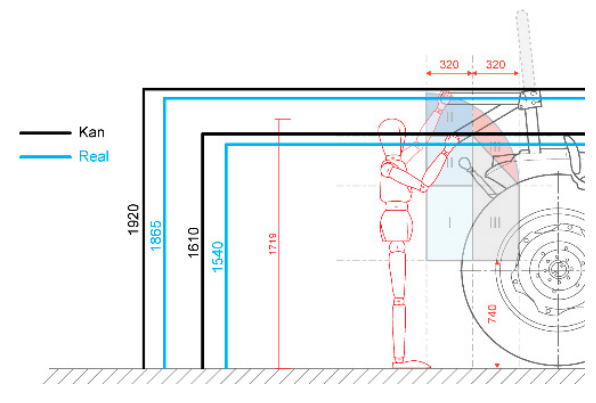

(b)

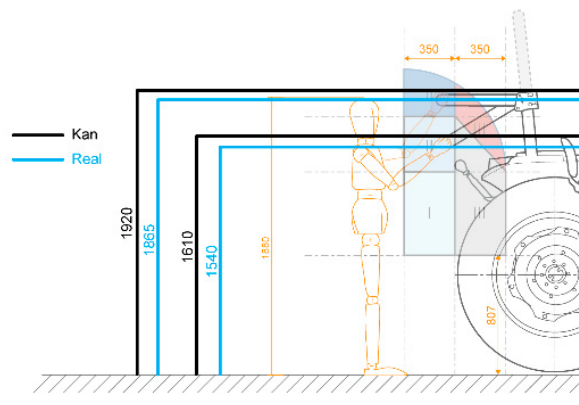

(c)

Figure 8. Distance from the ground to the manually operated part, both in the actual context and as reported in the KAN study 50 for: (a) the 5 th percentile, (b) the 50 th percentile, and (c) the 95th percentile.

In Figure 8, the three percentiles figures, with the respective redesigned accessible zones in interaction with the FROPS, are represented: the blue lines represent the height of gripping points at $45^{\circ}$ and $90^{\circ}$, measured in the real situation (based on [17]); whereas the black ones represent the heights of the gripping point suggested as optimal in the KAN Study 50 [45] for grasping machinery parts at the same angles of the roll-bar. Comparing the two lines for each position of the FROPS, it is possible to note how the dimensions recorded during on-field observations are just below the height values suggested as optimal in the KAN Study 50 for both the roll-bar angles.

Based on Figure 8, Table 2 reports the accessible zones in which the gripping point is at $45^{\circ}$ and $90^{\circ}$ roll-bar angle and the respective height from the ground (in actual and optimal conditions) for the three percentiles figures. With respect to the accessible zones, when the roll-bar is at $45^{\circ}$, the real and optimal gripping points fall within the new accessible zones or their extensions for all the three percentile figures, whereas, when the roll-bar is at an angle of $90^{\circ}$, the gripping points for the 50th and 95th percentile figures fall within the new accessible zones, while the gripping point of the 5th percentile is placed outside all the accessible zones, almost $300 \mathrm{~mm}$ above the extension of Zone II.

Table 2. Areas of the accessible zones in which the gripping point is at $45^{\circ}$ and $90^{\circ}$ roll-bar angle and respective height from the ground (in real and optimal conditions) for the three percentile figures.

\begin{tabular}{|c|c|c|c|c|}
\hline \multirow[b]{2}{*}{ Percentile } & \multicolumn{2}{|c|}{$\begin{array}{c}\text { Distance Ground-Gripping Point FROPS at } 45^{\circ} \\
\text { (Folded-Down Position) }\end{array}$} & \multicolumn{2}{|c|}{$\begin{array}{c}\text { Distance Ground-Gripping Point } \\
\text { FROPS at } 90^{\circ}\end{array}$} \\
\hline & $\begin{array}{c}1540 \mathrm{~mm} \\
\text { (from Observation) }\end{array}$ & $\begin{array}{l}1610 \mathrm{~mm} \\
\text { (KAN Study 50) }\end{array}$ & $\begin{array}{c}1865 \mathrm{~mm} \\
\text { (from Observation) }\end{array}$ & $\begin{array}{l}\text { 1920-2150 mm } \\
\text { (KAN Study 50) }\end{array}$ \\
\hline 5 th & Extension Zone II & Extension Zone II & / & / \\
\hline 50 th & Zone II & $\begin{array}{l}\text { Limit Extension } \\
\text { Zone II and Zone II }\end{array}$ & $\begin{array}{l}\text { Limit Extension } \\
\text { Zone II }\end{array}$ & / \\
\hline 95th & Zone II & Zone II & Extension Zone II & Extension Zone II \\
\hline
\end{tabular}

3.3. Tips for Technical Improvements to Be Fitted on Tractors and Testing against the New Accessible Zones

Based on the redesigned accessible zones, and to improve FROPS reachability, a design solution was developed which allowed operators to handle the FROPS standing with their feet on the ground and prevented them from adopting awkward and uncomfortable postures. In detail, through some design sketches adapted for each percentile considered, the research team decided to add a rod that would help operators perform the raising task (Figure 9). 


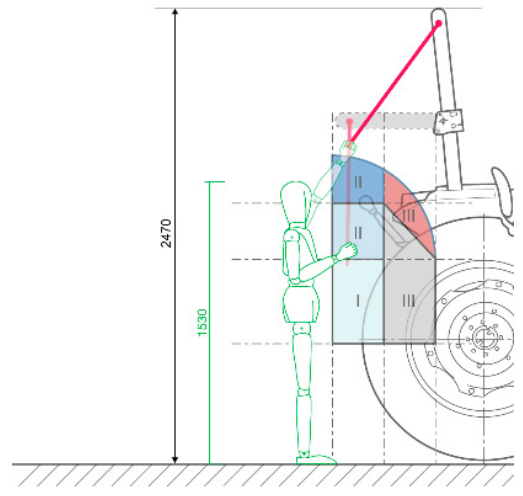

(a)

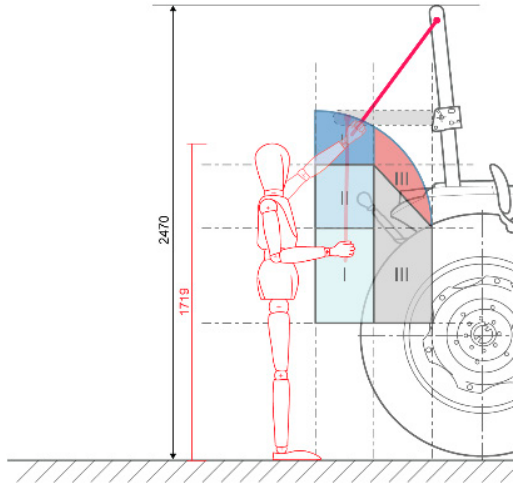

(b)

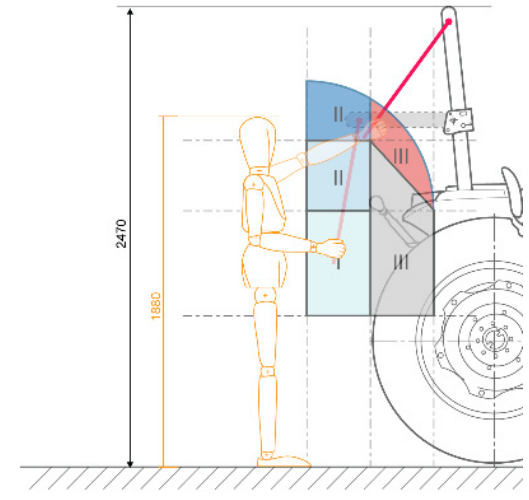

(c)

Figure 9. Sketches of the suggested solutions proposed, used by (a) the 5th percentile figure, (b) the 50th percentile figure, and (c) the 95th percentile figure, and its testing against the new accessible zones, to increase the users' reachability for FROPS handling.

A rod permanently fixed on the outer side and on the folding upper part of the FROPS has been identified as a possible solution. The rod was inserted on a threaded pin fastened on the FROPS and held in place by a nut. This connection allows the free rotation of the rod on the vertical plane; whereas, when the rod is in resting position, it is locked by a retainer placed in the lowest part of the FROPS. The rod, $800 \mathrm{~mm}$ long, can pivot on the vertical plane to be operated, enabling the operator to raise and lower the FROPS. See Figure 10 for more datails on the connection and retention solutions adopted.

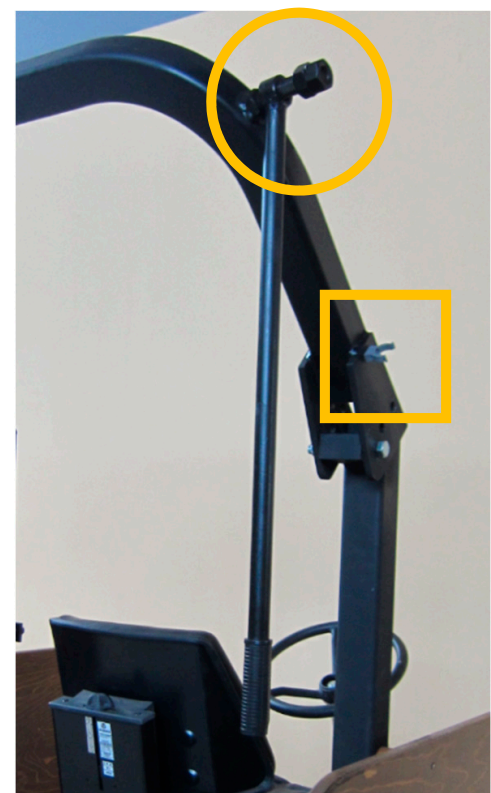

(a)

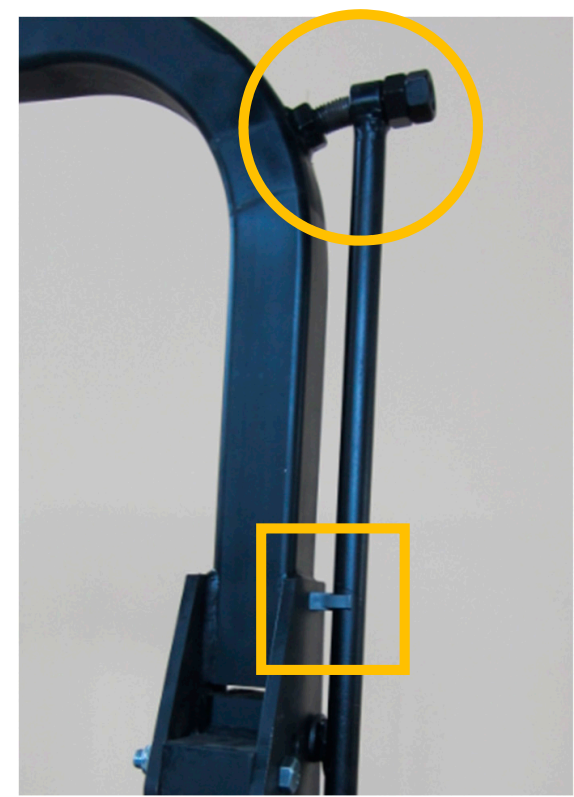

(b)

Figure 10. The rod proposed as a solution to increase FROPS reachability. In both figures (a,b), a coloured square highlights the fixing and connection joint of the rod with the FROPS, while a coloured circle highlights the retention mechanism to lock the rod when in rest position.

Finally, after that the prototype was fixed on the FROPS, it was tested thanks to the collaboration of a sample of three users representative of the three percentiles considered (5th, 50th, and 95th). The following figures show the three users while lifting the FROPS using the rod (Figure 11). 




(a)

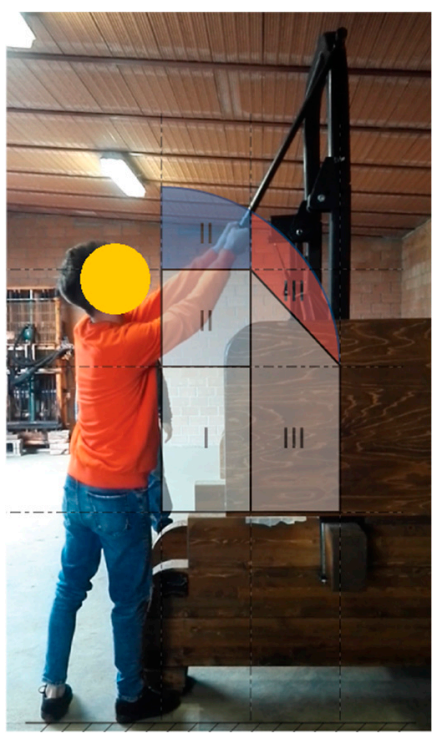

(b)

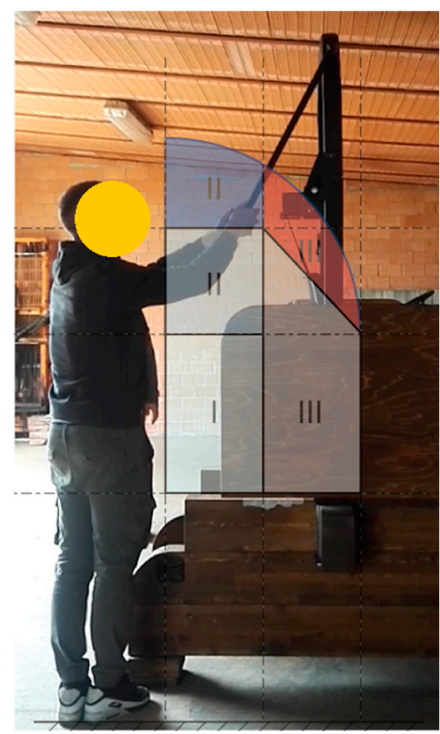

(c)

Figure 11. The three users corresponding to (a) the 5th percentile, (b) the 50th percentile, and (c) the 95th percentile involved in prototype testing, while performing the requested task of raising the FROPS. The redesigned accessible zones were overlapped to the photographs to verify their feasibility in actual conditions.

Photographs taken while performing the raising task show that the 2D representations made with manikins are rather loyal to the actual conditions. In detail, Figure 11 shows that all the participants belonging to the three percentiles considered could raise the FROPS standing safely with their feet on the ground, with the gripping point of the rod falling within the redesigned accessible zones. In addition, after performing the requested task, users expressed spontaneously their personal opinion related to the device just adopted. Overall, all three users said that "this handle is really useful for handling the FROPS" and "if it is available in the future on tractors, I will be eager to use it". In detail, the 5th percentile user expressed a greater appreciation for the device as "I found it simple to use", "handle adoption makes the task less tiring and standing with my feet on the ground, I can better manage the force to raise the FROPS, so I can feel safer and more confident". Furthermore, it would also provide a postural and behavioural advantage to the 50th percentile and 95th percentile operators, with the gripping point moving from Zone II to Zone I (Figure 9).

\section{Discussion}

In this study, the accessible zones for rear-FROPS handling on higher tractors were developed through the redesign of those provided in existing standards [3], by adapting them to the anthropometric variability represented by the 5 th, 50th, and 95th percentile of the European population [37], and also considering the functional aspects [45]. The results pointed out the relevance of considering the anthropometric variability when designing agricultural machinery and its components, focusing especially on reachability issues of the manually operated parts. Indeed, even though the accessible zones were adjusted to each of the three percentile figures considered (5th, 50th, and 95th), when the roll-bar was at an angle of $90^{\circ}$, the gripping point of the 5th percentile was placed outside all the accessible zones. To provide a gripping point falling within the adjusted accessible zones for the shorter users, we proposed a prototype solution that also represents an affordance for other stature percentiles, following the principles of "Inclusive Design" [46]. The suggested prototype design solution, i.e., the rod, has proven to be particularly appreciated by the users who tested it. It also has the advantages of a limited cost increase of the roll-bar, being easy to be stored on tractors, and available wherever necessary. This simple solution 
could respond to the needs expressed in previous on-field interviews and observations by the operators [17], who wish for some improvement of the FROPS handling.

However, concerning the FROPS reachability issue of the 5th percentile, the gripping point for these users is at the limit of the accessible zones regardless. Based on this, future studies may evaluate the feasibility of a telescopic rod. In this way, when the rod is at the minimum length, it would not hit other structural parts or components fixed on the tractor; whereas, when the rod reaches the maximum length, it would be longer than the one tested in the present study, thus further reducing the distance from the gripping point and improving rear-mounted FROPS handling for the shorter users. Based on the present results, a set of guidelines for designing and testing possible alternative FROPS design solutions in compliance with the resized and adjusted accessible zones may be developed.

Whenever the proposed solution should be adopted on a FROPS intended for the market, it should be installed on the items submitted to the ROPS test to verify that its installation does not undermine the results of the test itself and that all the conditions of acceptance provided by the OECD Code for the test are fulfilled. Installing such a simple structure on an existing FROPS would require redoing the ROPS tests because, depending on how the rod is connected to the FROPS body, by drilling or welding, it might discredit the results of the test performed on the FROPS, compromising its efficiency in protecting the operator in case of overturning. In addition, in future studies, the fixing method needs to be tested to verify that the retention mechanism guarantees the rod remains fixed on the outside of the FROPS in case of roll-over and does not infringe the operator's clearance zone. During the designing phase, it is essential to take into account the target market and the anthropometric differences of the populations to which the machine is addressed. This is particularly important for agricultural machinery manufacturing, which is a highly integrated industry with globally marketed products [47]. Respecting anthropometric variability and paying special attention to operators belonging to the 5 th percentile, which are particularly disadvantaged in the interaction with components placed at a greater distance from the ground, is crucial in the design of products which are intended for populations with a high inter- and intravariability based on geographical areas (e.g., Northern vs. Southern European populations [37]), gender (relevant for the increasing rate of women in the farming population [48]), and age (relevant for the increasing rate of older farming populations $[48,49])$.

The design of a rod, or also a telescopic rod, to make the gripping point closer to the operator allows all the percentiles figures to handle the FROPS easily and enhances safety for shorter people, who, in previous on-field studies, were observed climbing muddy and unstable parts of the machinery to grasp the roll-bar [17]. However, technical improvements could not be sufficient to solve safety issues in the human-machine interaction [50]. Therefore, in case of changes in technical features or a new design, it is recommended to introduce information and training activities to promote the correct behaviour and use of the proposed solution [51]. Many previous studies have indeed highlighted the role of training in enhancing safety knowledge and behaviour in a sector such as agriculture, characterised by complex and varied tasks [52-54], showing the high efficacy of visual materials $[51,55,56]$ for both local $[57,58]$ and migrant farmworkers $[59,60]$, who represent a relevant percentage of the agricultural workforce in developed countries [61]. In line with this, the 2D graphical representation of the adjusted accessible zones developed in the present study could also be included in users' manuals and training materials to overcome cultural and language barriers in showing operators not only how to comfortably and safely operate the FROPS, but also the focus on human variability adopted during the design process of the machinery and its parts.

\section{Limitation and Future Developments of the Present Study}

Some limitations of the present study should be acknowledged. The suggestions and improvements provided have been tested with a group of one user per percentile considered. In the future development of the research, it will be useful to test the suggested 
solutions with a larger group of agricultural operators to also investigate the acceptability and the usability of the proposed devices, to promote the comfortable and correct FROPS operation for all users.

Regarding the variability issues, in the future development of the research, it could be beneficial to further verify the accessible zones developed in the present investigation among women and workers with different anthropometric characteristics compared to the European population. Furthermore, it would be useful to involve participants with different previous working experience and ages, considering the decrease in strength and joint mobility with ageing and reduced mobility caused by musculoskeletal disorders (MSD) and injuries [62-66]. In addition, considering that, as reported by NASA RP 1024, the percentiles within a category of data are indeed exclusive, the use of anthropometric manikins designed with the same percentile of all measures can be improved by considering also the variability of the proportions between the different body segments in individuals from both single populations and different populations.

Finally, in this phase of the research, the adoption of the 2D representation was considered as able and sufficient to point out how human variability can influence the safety behaviours and the users' interaction with the tractor components. The 2D technical drawing adopted is also consistent with the technical representation used in the OECD Codes, and it is recognised as essential for communicating ideas in industry and engineering [67]. However, the authors acknowledge that, in future developments, it could be helpful to perform a deeper analysis using 3D simulation software which will allow reproducing the dynamics of the actual operating conditions.

\section{Conclusions}

To improve the on-field observed critical interaction between the users and the FROPS, in the present study, the accessible zones for FROPS operation provided by the OECD Codes were resized and adjusted according to the anthropometric characteristics. Building on this, a solution was suggested to benefit the shorter users in FROPS handling and, as a consequence, also the taller ones. In conclusion, the present study highlighted that it is no longer possible to follow the principle of "designing for the average", which is primarily being used when adjustability is not practical [68], to design industrial equipment and machinery; the design must take into account those users who may have greater difficulties in the interaction with machinery components, especially in terms of reachability. The outcomes of the present research provide knowledge and evidence to regulatory and standardisation bodies; they support a broad reflection on the extent to which human variability should be considered in machinery design, and its impact on thematic policies (e.g., occupational health and safety) in relation to the societal challenges. In particular, the present study represents a contribution to introducing ergonomic requirements for rear-mounted FROPS fitted on standard tractors, such as those considered in the OECD Code 4.

Author Contributions: Conceptualisation, M.M.C., L.V., F.C., G.P., and E.C.; methodology, M.M.C., L.V., F.C., and E.C.; investigation, M.M.C., L.V., F.C., G.P., and E.C.; data curation, L.V.; data analysis, M.M.C. and L.V.; writing - original draft preparation, M.M.C., L.V., and F.C.; writing — review and editing, M.M.C., L.V., F.C., G.P., and E.C.; supervision, E.C.; project administration, E.C. All authors have read and agreed to the published version of the manuscript.

Funding: This research was funded by the Universidad de León. C.F. acknowledges the PhD grant from the FPU program of the Spanish Science and Innovation Ministry (Ref. FPU18/04934).

Institutional Review Board Statement: The study was conducted according to the guidelines of the Declaration of Helsinki, and approved by the Research Advisory Group of the Institute for Agricultural and Earthmoving Machines (IMAMOTER, now Institute of Sciences and Technologies for Sustainable Energy and Mobility, STEMS) of the National Research Council of Italy (CNR) on 10.04.2019. 
Informed Consent Statement: Written informed consent was obtained from all the subjects involved in the study.

Data Availability Statement: Data available on request.

Conflicts of Interest: The authors declare no conflict of interest.

\section{References}

1. Abubakar, M.S.; Ahmad, D.; Akande, F.B. A Review of Farm Tractor Overturning Accidents and Safety. Pertanika J. Sci. Technol. 2010, 18, 377-385.

2. Pessina, D.; Facchinetti, D.; Giordano, D.M. Narrow-track agricultural tractors: A survey on the load of the hand-operated foldable rollbar. J. Agric. Saf. Health 2016, 22, 275-284.

3. OECD (Organisation for Economic Co-Operation and Development). Code 4-OECD Standard Code for the Official Testing of Protective Structures on Agricultural and Forestry Tractor; OECD: Paris, France, 2019.

4. Facchinetti, D.; Santoro, S.; Galli, L.E.; Pessina, D. Agricultural Tractor Roll-Over Related Fatalities in Italy: Results from a 12 Years Analysis. Sustainability 2021, 13, 4563. [CrossRef]

5. Cavallo, E.; Ferrari, E.; Coccia, M. Likely technological trajectories in agricultural tractors by analysing innovative attitudes of farmers. Int. J. Technol. Policy Manag. 2015, 15, 158-177. [CrossRef]

6. Cavallo, E.; Langle, T.; Bueno, D.; Tsukamoto, S.; Görücü, S.; Murphy, D. Rollover Protective Structure (ROPS) Retrofitting on Agricultural Tractors: Goals and Approaches in Different Countries. J. Agromed. 2014, 19, 208-209. [CrossRef]

7. Caffaro, F.; Schmidt, S.; Murphy, D.J.; Cavallo, E. Comprehension rates of safety pictorials affixed to agricultural machinery among Pennsylvania rural population. Saf. Sci. 2018, 103, 162-171. [CrossRef]

8. Franceschetti, B.; Rondelli, V.; Ciuffoli, A. Comparing the influence of Roll-Over Protective Structure type on tractor lateral stability. Saf. Sci. 2019, 115, 42-50. [CrossRef]

9. ANSI (The American National Standards Institute)/ ASABE (The American Society of Agricultural and Biological Engineers). ANSI/ASAE S390.5 JAN2011 Definitions and Classifications of Agricultural Field Equipment; ASABE: St. Joseph, MI, USA, 2011.

10. European Parliament. Regulation No 167 /2013 of the European Parliament and of the Council of 5 February 2013 on the Approval and Market Surveillance of Agricultural and Forestry Vehicles; European Parliament: Strasbourg, France, 2013. Available online: https: / / eur-lex.europa.eu/legal-content/EN/TXT/HTML/?uri=CELEX:32013R0167\&from=EN (accessed on 7 May 2021).

11. Guzzomi, A.; Rondelli, V. Narrow-track wheeled agricultural tractor parameter variation. J. Agric. Saf. Health 2013, 19, 237-260.

12. Guzzomi, A.; Rondelli, V.; Capacci, E. Operator protection in roll-over events of articulated narrow track tractors. Biosyst. Eng. 2019, 185, 103-115. [CrossRef]

13. OECD (Organisation for Economic Co-operation and Development). Code 6-OECD Standard Code for the Official Testing of Front Mounted Roll-Over Protective Structures on Narrow-Track Agricultural and Forestry Tractors; OECD: Paris, France, 2019.

14. OECD (Organisation for Economic Co-operation and Development). Code 7-OECD Standard Code for the Official Testing of Rear Mounted Roll-Over Protective Structure on Narrow-Track Agricultural and Forestry Tractors; OECD: Paris, France, 2019.

15. CEMA (European Agricultural Machinery Association). Stable Year for Tractor Registrations in 2019. Available online: www. cema-agri.org (accessed on 12 June 2021).

16. Caffaro, F.; Micheletti Cremasco, M.; Giustetto, A.; Vigoroso, L.; Paletto, G.; Cavallo, E. Ergonomics in Agriculture: Critical Postures, Gestures, and Perceived Effort in Handling Foldable Roll-Over Protective Structures (ROPS) Fitted on Tractors. In Proceedings of the 20th Congress of the International Ergonomics Association (IEA 2018), Florence, Italy, 26-30 August 2018; Springer: Cham, Switzerland, 2019; Volume 819. [CrossRef]

17. Micheletti Cremasco, M.; Caffaro, F.; Giustetto, A.; Vigoroso, L.; Paletto, G.; Cavallo, E. Tractor Rollover Protection: Is the Incorrect Use of Foldable Rollover Protective Structures Due to Human or to Technical Issues? Hum. Factors 2020, 62, 64-76. [CrossRef]

18. García-Ramos, F.J.; Val-Agüasca, J.; Martín-Ramos, P.; Videgain-Marco, M.; Boné-Garasa, A.; Vidal-Cortés, M.; Mangado, J.; Jarén, C.; Arnal, P.; López-Maestresalas, A.; et al. Siniestralidad, Mortalidad Agrícola, Vuelcos de Tractores e Incendios en Cosechadoras 2010-2019; Fundación MAPFRE: Madrid, Spain, 2020. Available online: https://app.mapfre.com/documentacion/publico/i18n/ catalogo_imagenes/grupo.do?path=1104857 (accessed on 7 May 2021).

19. NIOSH. Fatality Assessment and Control Evaluation (Face) Program; NIOSH: Washington, DC, USA, 2015.

20. Rondelli, V.; Casazza, C.; Martelli, R. Tractor roll-over fatalities, analysing accident scenario. J. Saf. Res. 2018, 67, 99-106. [CrossRef] [PubMed]

21. Pessina, D.; Facchinetti, D. Fitting and testing roll-over protective structures on self-propelled agricultural machinery. J. Agric. Eng. 2013, 44, 736-741. [CrossRef]

22. Hoy, R.M. Farm tractor roll-over protection: Why simply getting roll-over protective structures installed on all tractors is not sufficient. J. Agric. Saf. Health 2009, 15, 3-4.

23. Khorsandi, F.; Ayers, P.D.; Jackson, D.; Wilkerson, J. The effect of speed on foldable ROPS actuation forces. J. Agric. Saf. Health 2016, 22, 285-298.

24. Ferguson, T.; Greene, M.; Repetti, F.; Lewis, K.; Behdad, S. Combining Anthropometric Data and Consumer Review Content to Inform Design for Human Variability. In Proceedings of the ASME 2015 International Design Engineering Technical Conferences and Computers and Information in Engineering Conference, Boston, MA, USA, 2-5 August 2015; pp. 1-13. 
25. Feyzi, M.; Navid, H.; Dianat, I. Ergonomically based design of tractor control tools. Int. J. Ind. Ergon. 2019, 72, 298-307. [CrossRef]

26. Kushwaha, D.K.; Kane, P.V. Ergonomic assessment and workstation design of shipping crane cabin in steel industry. Int. J. Ind. Ergon. 2016, 52, 29-39. [CrossRef]

27. Naumann, A.; Roetting, M. Digital Human Modeling for Design and Evaluation of Human-Machine Systems. MMI Interakt. 2007, 12, 27-35.

28. Pheasant, S.; Haslegrave, C.M. BodySpace. In Anthropometry, Ergonomics and the Design of Work, 3rd ed.; Taylor \& Francis Group: Boca Raton, FL, USA, 2015.

29. Ogawa, K. The role of design guidelines in assisting the interface design task. In Proceedings of the Human Factors and Ergonomics Society 37th Annual Meeting, Seattle, WA, USA, 11-15 October 1993.

30. Persson, H.; Åhman, H.; Yngling, A.A.; Gulliksen, J. Universal design, inclusive design, accessible design, design for all: Different concepts-One goal? On the concept of accessibility-Historical, methodological and philosophical aspects. Univ. Access Inf. Soc. 2014, 14, 505-526. [CrossRef]

31. European Commission. Guide to Application of the Machinery Directive 2006/42/EC 2010:408. Available online: https: / / eur-lex.europa.eu/LexUriServ /LexUriServ.do?uri=OJ:L:2006:157:0024:0086:EN:PDF (accessed on 7 May 2021).

32. Ayers, P.; Khorsandi, F.K.; Poland, M.J.; Hilliard, C.T. Foldable roll-over protective structures: Universal lift-assist design. Biosyst. Eng. 2019, 185, 116-125. [CrossRef] [PubMed]

33. Pessina, D. An Assistive Technology Application for Narrow Tractors ROPS. In Proceedings of the Innovation Technology to Empower Safety, Health and Welfare in Agriculture and Agro-Food Systems, Ragusa, Italy, 15-17 September 2008 ; pp. 302-310.

34. Ayers, P.; Khorsandi, F.; Wang, X.; Araujo, G. ROPS designs to protect operators during agricultural tractor roll-overs. J. Terramech. 2018, 75, 49-55. [CrossRef]

35. Franceschetti, B.; Rondelli, V. Models to predict the force to operate front foldable roll-over protective structures for narrow-track tractors. Biosyst. Eng. 2019, 185, 126-134. [CrossRef]

36. Haselsteiner, A.F.; Reisenhofer, R.; Ohlendorf, J.H.; Thoben, K.D. Design for extremes: A contour method for defining requirements based on multivariate extremes. In Proceedings of the Design Society: International Conference on Engineering Design, Delft, The Netherlands, 5-8 August 2019; pp. 1433-1442.

37. Jurgens, H.W.; Matzdorff, I.; Windberg, J. International Anthropometric Data for Work-Place and Machinery Design. 1998. Available online: https:/ / www.baua.de/DE/Angebote/Publikationen/AWE/AWE108e.pdf?_blob=publicationFile\&v=2 (accessed on 5 May 2021).

38. Webb Associates. Anthropometric Source Book; NASA Reference Publication No. 1024; Lyndon, B., Ed.; Johnson Space Center, Aeronautics and Space Administration: Houston, TX, USA, 1978.

39. Norris, B.; Wilson, J.R. Childata: The Handbook of Child Measurements and Industry. Capabilities. Data for Design Safety; Department of Trade and Industry: London, UK, 1995.

40. Open Ergonomics Ltd. PeopleSize; Open Ergonomics: Loughborough, UK, 2020. Available online: https://openerg.com/psz/ index.html (accessed on 7 May 2021).

41. Peebles, L.; Norris, B. Adultdata: The Handbook of Adult Anthropometric and Strength Measurements: Data for Design Safety; Department of Trade and Industry: London, UK, 1998.

42. ISO (International Organization for Standartization). ISO 7250-1:2017 Basic Human Body Measurements for Technological Design-Part 1: Body MEASUREMENT Definitions and Landmarks; ISO: Geneva, Switzerland, 2017.

43. ISO (International Organization for Standartization). ISO 14738:2009 Safety of Machinery-Anthropometric Requirements for the Design of Workstations At Machinery; ISO: Geneva, Switzerland, 2009.

44. ISO (International Organization for Standartization). ISO 547-3:2009 Safety of Machinery—Human Body Measurements. Part 3: Anthropometric Data; ISO: Geneva, Switzerland, 2009.

45. KAN Study 50. Operating Forces on Agricultural Machinery. Analysis and Measurement of Manual Operating Forces. Resulting Recommendations. 2013. Available online: https://www.kan.de/fileadmin/Redaktion/Dokumente/KAN-Studie/en/2013 _KAN-study_operatingForces-en.pdf (accessed on 15 June 2021).

46. Molenbroek, J.F.M.; Dekker, M.C. Exploring the boundaries of Design for All. In Meeting Diversity in Ergonomics; Elsevier: Amsterdam, The Netherlands, 2006; pp. 2-6.

47. CEMA (European Agricultural Machinery Association). European Agricultural Machinery Industry. CEMA Priorities and Key Figures Advancing Agricultural Machinery and Solutions for Sustainable Farming 2019. Available online: www.cema-agri.org (accessed on 15 June 2021).

48. European Commission. Females in the Field: More Woman Managing Farms across Europe 2019. Available online: https: / / ec.europa.eu/info/news/queens-frontage-women-farming-2019-mar-08_en (accessed on 5 May 2021).

49. Koolhaas, W.; Van Der Klink, J.J.L.; Groothoff, J.W.; Brouwer, S. Towards a sustainable healthy working life: Associations between chronological age, functional age and work outcomes. Eur. J. Public Health 2012, 22, 424-429. [CrossRef]

50. Stahre, J. Evaluating human/machine interaction problems in advanced manufacturing. Comput. Integr. Manuf. Syst. 1995, 8, 143-150. [CrossRef]

51. Caffaro, F.; Bagagiolo, G.; Cremasco, M.M.; Cavallo, E. Participatory Ergonomic Design of a Safety Training Tool for Migrant Workers in Agriculture. Chem. Eng. Trans. 2017, 58, 25-30. 
52. Bechar, A.; Vigneault, C. Agricultural robots for field operations. Part 2: Operations and systems. Biosyst. Eng. 2017, 153, 110-128. [CrossRef]

53. Caffaro, F.; Micheletti Cremasco, M.; Roccato, M.; Cavallo, E. It does not occur by chance: A mediation model of the influence of workers' characteristics, work environment factors, and near misses on agricultural machinery-related accidents. Int. J. Occup. Environ. Health 2017, 23, 52-59. [CrossRef]

54. Meyers, J.M.; Faucett, J.; Tejeda, D.G.; Kabashima, J.; Miles, J.A.; Janowitz, I.; Duraj, V.; Smith, R.; Weber, E. High risk tasks for musculoskeletal disorders in agricultural field work. In Proceedings of the Human Factors and Ergonomics Society 44th Annual Meeting, San Diego, CA, USA, 30 July-4 August 2000; SAGE Publications: Los Angeles, CA, USA, 2000; pp. 616-619.

55. Arcury, T.A.; Estrada, J.M.; Quandt, S.A. Overcoming language and literacy barriers in safety and health training of agricultural workers. J. Agromed. 2010, 15, 236-248. [CrossRef]

56. Bello-Bravo, J.; Dannon, E.; Agunbiade, T.; Tamo, M.; Pittendrigh, B.R. The prospect of animated videos in agriculture and health: A case study in Benin. J. Educ. Dev. Using ICT 2013, 9, 4-16.

57. Brandt, V.; Struttmann, T.; Cole, H.; Piercy, L. Delivering Health Education Messages for Part-Time Farmers through Local Employers. J. Agromed. 2001, 7, 23-30. [CrossRef]

58. Smith, S.W.; Rosenman, K.D.; Kotowski, M.R.; Glazer, E.; Mcfeters, C.; Keesecker, N.M.; Law, A. Using the EPPM to Create and Evaluate the Effectiveness of Brochures to Increase the Use of Hearing Protection in Farmers and Landscape Workers. J. Appl. Commun. Res. 2008, 36, 200-218. [CrossRef]

59. Brunette, M.J. Development of educational and training materials on safety and health: Targeting Hispanic workers in the construction industry. Fam. Community Health 2005, 28, 253-266. [CrossRef]

60. Caffaro, F.; Micheletti Cremasco, M.; Bagagiolo, G.; Vigoroso, L.; Cavallo, E. Effectiveness of occupational safety and health training for migrant farmworkers: A scoping review. Public Health 2018, 160, 10-17. [CrossRef]

61. Martin, P.L. Migrant Workers in Commercial Agriculture; ILO: Geneva, Switzerland, 2016.

62. Bohannon, R.W. Grip strength: An indispensable biomarker for older adults. Clin. Interv. Aging 2019, 14, 1681-1691. [CrossRef] [PubMed]

63. De Oliveira Medeiros, H.B.; De Araújo, D.S.M.S.; De Araújo, C.G.S. Age-related mobility loss is joint-specific: An analysis from 6,000 Flexitest results. Age 2013, 35, 2399-2407. [CrossRef]

64. Doriot, N.; Wang, X. Effects of age and gender on maximum voluntary range of motion of the upper body joints. Ergonomics 2006, 49, 269-281. [CrossRef] [PubMed]

65. Micheletti Cremasco, M.; Lorè, A.; Re, A.; Caffaro, F.; Liubicich, M.E.; Magistro, D.; Roggero, A. Anthropometric and Ergonomic approach to the ageing: The importance of the multidisciplinary study in the act on ageing project (Piedmont region). J. Biol. Res. 2012, 85, 276-277. [CrossRef]

66. Caffaro, F.; Lundqvist, P.; Micheletti Cremasco, M.; Nilsson, K.; Pinzke, S.; Cavallo, E. Machinery-related perceived risks and safety attitudes in senior Swedish farmers. J. Agromed. 2018, 23, 78-91. [CrossRef]

67. ISO (International Organization for Standartization). ISO 128-1:2020 Technical Product Documentation (TPD)—General Principles of Representation-Part 1: Introduction and Fundamental Requirements; ISO: Geneva, Switzerland, 2020.

68. Taifa, I.W.; Desai, D.A. Anthropometric measurements for ergonomic design of students' furniture in India. Eng. Sci. Technol. Int. J. 2017, 20, 232-239. [CrossRef] 